\title{
Brain Drain in New Zealand: Issues, Evidence and Implications
}

\author{
Wai Kin Choy and Hayden Glass
}

$\mathrm{T}$ There is public concern that New Zealand is experiencing a 'brain drain' the loss of a large number of its brightest citizens to other countries. Some of the related public policy issues are discussed in this paper. The paper begins with an outline of possible reasons for concern about a brain drain. This is followed by a summary of the available evidence on whether New Zealand is actually experiencing a brain drain, examining the numbers of emigrants and immigrants, and their skill and age compositions over time. The focus is on the aggregate picture, rather than specific occupational categories. More detailed discussions of the evidence can be found in Glass and Choy (2001). The paper also presents some thoughts on the related policy implications.

\section{When a Brain Drain Is of Concern}

A brain drain refers to the numbers of emigrants and immigrants (that is, a brain drain is a net outflow of people), or to their attributes (that is, a brain drain is a net outflow of the high-skilled or the highly-experienced). The latter tends to be the interpretation normally adopted, and is the focus of this paper.

A net outflow per se may be of public policy concern if one believes that a certain critical mass is needed to support the nation's development and progress, that is, if a larger population is needed to achieve economies of scale and higher rates of economic growth and improved living standards. The problem lies in determining what the optimal size is.

Net outflows may not be the only cause for concern. If the people leaving and entering the country are different in some relevant way, there may still be concerns even if there were no net outflows. Similarly, a country may not be better off just because there are net inflows (say, there were zero population growth, all the people leaving were high-skilled and all the immigrants were lowskilled). Therefore, the composition of both the inflows and outflows matters. A net loss of skilled workers is equivalent to a reduction in the domestic human capital stock and may be of concern.

The key link between living standards and the skill composition of migration flows is through income - a central component of living standards. The key to

Wai Kin Choy was a policy analyst at the New Zealand Treasury, and Hayden Glass was an economist with the Law and Economics Consulting Group (LECG) when this paper was written. The views expressed are those of the authors and do not necessarily reflect the views of the New Zealand Treasury or of LECG. 
higher per capita incomes is productivity. One crucial contributing factor to higher productivity is skilled workers (see Claridge and Box, 2000). They are better at creating, improving and applying new knowledge, which stimulates technological advance and thus productivity.

The impact of changes in the skill composition of the labour force on production and productivity depends on the degree of complementarity between skilled labour and the other inputs of production - capital and unskilled labour. The impact of a brain drain on productivity depends partially on whether skilled workers compete with unskilled workers (are 'substitutes' for them), or enhance their productivity (are 'complements' for them).

There is empirical support for complementarity between skilled labour and capital (Krusell et al., 1997; Golden and Katz, 1998). However, evidence on the degree of complementarity between skilled and unskilled labour is mixed (see Hamermesh, 1993). To the extent that they are complements, a reduction in the number of skilled workers, as would occur with a brain drain, would lower the average productivity of the economy and hence the earnings of less skilled workers and the return on capital. It would also have the effect of raising the productivity of remaining high-skilled workers. The overall effect on productivity depends on the degree of complementarity and the shares of high- and low-skilled workers in the labour force. It is possible that a brain drain could be harmful for the source country in aggregate (see Bhagwati and Hamada, 1974).

The 'new growth' literature suggests that the negative implications of a brain drain on the source country are magnified. For example, Hague and Kim (1995) posit that the emigration of people with high levels of human capital reduces the growth rate of the effective human capital that remains in the economy, and thus generates a reduction of per capita growth in the source country.

Under this scenario, not only is high-skilled labour complementary with capital and low-skilled labour, but high-skilled workers enhance technological innovations and their diffusion. There could also be significant learning-by-doing. The main implication is that a continuous outflow of high-skilled labour would deplete the source country's level of human capital and thus reduce that country's capacity to achieve as much technological progress as other economies.

Both the standard and new growth models have recently been challenged in various theoretical papers that examine the impact of migration on human capital formation within a context of rationed migration flows (see Beine, Docquier and Rapoport, 2001; Mountford, 1997; Stark, Helmenstein and Prskawetz, 1997). These theoretical papers assume that workers weigh the costs of acquiring skills against prospective market rewards for enhancing skills, both at home and abroad, and make optimizing decisions. The possibility of migration changes the opportunity set and the incentive structure. In particular, the assumed higher returns to education abroad create an incentive for the population to upskill and increase their human capital. In the extreme, if there are large numbers of people trying to compete in the international labour market, then there will be an increase in the level of education acquisition in the home country. Given that only a fraction of the educated residents will emigrate (via some rationing device either 
from the destination country, or by the source country), the average level of education of the remaining population in the source country would increase. This is known as the ex ante 'brain gain effect'.

The argument above depends on there being some rationing. ${ }^{1}$ Where there are free flows of people, the scope of this mechanism can be greatly reduced or even eliminated. For example, due to the lack of rationing under the TransTasman Travel Arrangement (TTTA) between New Zealand and Australia, it is unlikely that workers in New Zealand who upskill themselves in the expectation of higher returns to their skill in Australia will actually remain in New Zealand. However, for other country destinations - where rationing still applies - the ex ante brain gain effect may hold.

The crucial question then is which effect dominates - the ex ante brain gain effect (migration prospects fostering investments in education because of higher returns abroad) or the ex post brain drain effect (that is, educated agents actually migrating). If the first effect dominates, then the average level of human capital is higher in the economy open to migration than in the closed economy. In such circumstances, there will be a 'beneficial brain drain' (see Beine, Docquier and Rapoport, 2001; Mountford, 1997). This is an empirical question to be determined. Unfortunately, there is relatively little empirical work on this (see Carrington and Detragiache, 1999:7).

If there is significant return migration, then the loss of highly trained personnel at any one time can have beneficial impacts on the source countries in the medium to longer run. This is why some people have labelled this kind of scenario a 'brain circulation' rather than a 'brain drain' (for example, Johnson and Regets, 1998). The level of productivity and hence, the national welfare may rise if those skilled workers who went abroad return to the home country with improved productivities. The critical question then is whether there is in fact return migration and what the profile of migrants returning to the source country looks like. Even in a situation of ongoing net outflows, if the returnees are more skilled than those leaving, the net economic impact on the country might not be negative.

In short, a drain of brains and a welfare gain need not be mutually exclusive. In fact, a drain of brains can be the very cause of a welfare gain if it stimulates human capital acquisition in those that remain, or leads to higher-skilled return migration.

But it is not all good news. Based on the theoretical literature, there would be cause for public policy concern if there were large net outflows of the high-skilled

\footnotetext{
1 A referee argued that it is difficult to see how a rationing of migration opportunities abroad would necessarily raise education levels in the home country, unless the rationing was unforeseen. If the rationing were anticipated, it would probably reduce the expected returns to tertiary education, and thus reduce the ex ante brain gain effect. But because of the pervasive uncertainty about the returns to skills and education, either an under-investment or over-investment (from the individual's perspective) could still occur. Having said that, this point is merely to illustrate that it is possible for large migration flows at a particular point in time to benefit the source country.
} 
over the long term, and there was no rationing of emigrant numbers to other countries, and little return migration.

Those in the working age population are usually assumed to be net contributors to the economy (particularly in the labour market). Such contributions help determine the standard of living for the average person in the population. Therefore, even if there are net outflows, one needs to look at the age composition of the flows. Departures of those who do not fall into the working age category arguably would not raise as much economic alarm as if there were large departures of working age people.

Age composition is also important as a proxy for the amount and breadth of work or business experience that a migrant has. For this reason, from a public policy standpoint, we should be more concerned if we are losing the older group from the working age population than the younger groups.

There are numerous social impacts from emigration and immigration (see New Zealand Institute of Economic Research, 1994; and 1996). For example, changes in ethnic and cultural diversity can influence how current New Zealanders adjust to new residents and citizens and the changes they bring to national identity. There could be a lower critical mass for maintaining existing New Zealand culture, resulting in change in national identity and culture.

A brain drain could also have significant negative fiscal effects for the remaining population including through:

- Education investments - Most education services are substantially funded by taxpayers, who therefore have an interest in getting a return on that investment in the form of taxes from the educated person over his/her life. To the extent that educated people take their accumulated education overseas with them, the implicit contract with taxpayers is thwarted. New Zealand taxpayers end up, in effect, subsidising the growth of other countries. The effect is stronger to the extent that the educated can avoid paying their contribution by avoiding taxes or student loan repayments.

- Other fiscal costs - New Zealanders qualify for subsidised health care by birth or by securing permanent residence. They can qualify for superannuation by working or living here for a minimum period. There is a risk that New Zealanders will go overseas and avoid the tax that could be expected to fund these costs, and return to New Zealand for health care or for superannuation at the cost of those who remain behind.

These non-economic impacts could be significant. But, as with the concerns about the numbers of flows per se, their implications for public policy on the brain drain are inconclusive.

This section has covered various reasons why public policy might be concerned with a brain drain. Broadly speaking, policy makers should be concerned if: 
- there are net outflows of the high-skilled and no rationing exists in the destination country (because then the ex ante brain gain effect does not apply);

- there are net outflows of the highly-experienced (those in the middle or late working age population groups); and

- there is limited return migration.

\section{The Evidence}

This section summarises very briefly the evidence on the numbers, skill composition and age of migrant flows to and from New Zealand (see Glass and Choy, 2001 for more detailed evidence). We consider migration flows between New Zealand and the rest of the world (all countries, including Australia), and the flows between New Zealand and Australia.

The primary source of international migration data is the arrival and departure cards. The arrival card records, inter alia, how long people have been away from New Zealand (for residents) or how long they intend to stay in New Zealand (if they are not residents). The departure card records how long people intend to be away from New Zealand (for residents), or how long they have stayed (for nonresidents). From their answers on these cards, people are classified as either Permanent and Long-term (PLT) Migrants, who were away or intend to stay away from their home country at least a year; or Short-term Visitors, who were away or intend to stay away less than a year. The main caveats on the use of this data have already been covered extensively in the literature (see Glass and Choy, 2001; Carmichael, 1993a; and 1993b).

Figure 1 shows permanent and long-term (PLT) migration flows to and from New Zealand between 1961 and 2001. The general New Zealand convention to analyse the data using years ending March is followed throughout this paper (see Bedford and Bedford, 2001 for an update on the 2001 September quarter international migration statistics). The net total migration flow is shown alongside the net PLT series. The net total series is one way of accounting for changes in people's intended duration of stay (see Bedford, 2001 and Glass and Choy, 2001).

While there are net PLT outflows recently to the rest of the world, they are small, cyclical and follow a long period of inflows. In the longer term (for example, 10 years or 40 years), New Zealand gains people from migration. The short-term statistic (net PLT) can give a misleading picture. Accounting for changes in people's intentions (net total) seems to suggest net inflows recently. Given this volatility in short term figures, it is important to view migration over the medium to long-term. 


\section{Figure 1: New Zealand Migration Flows 1961-2001}

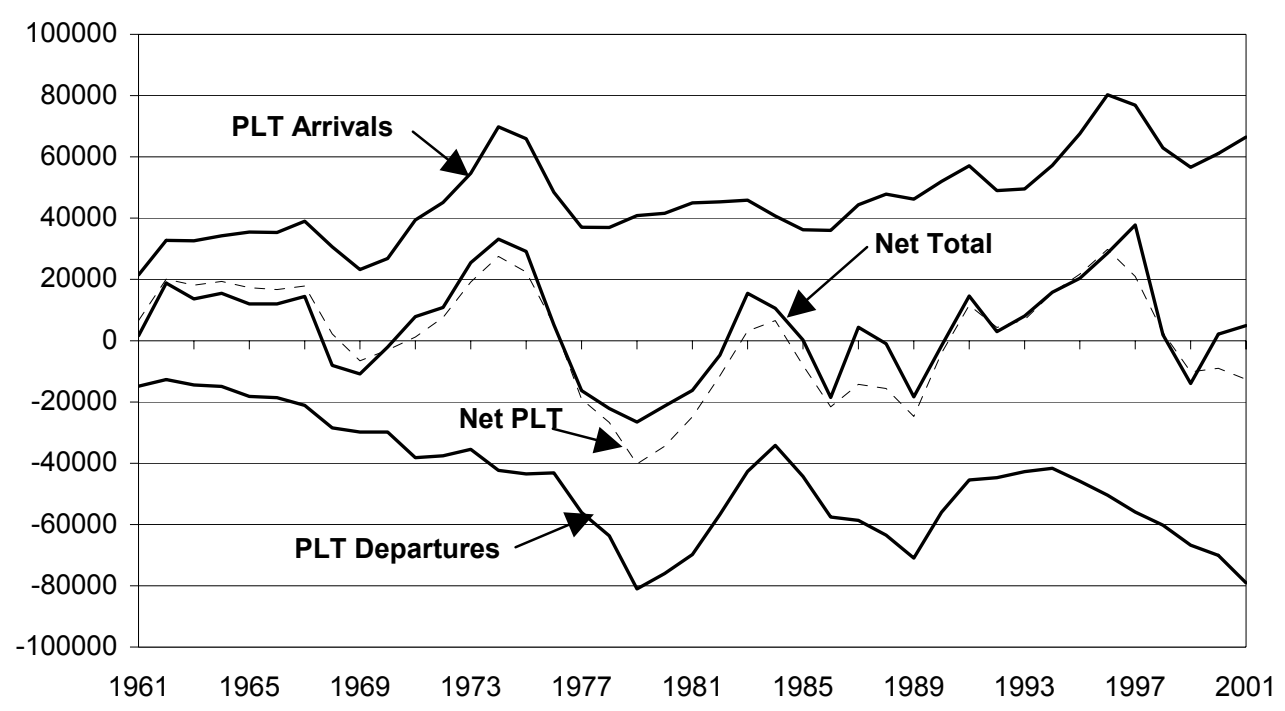

Although not shown in the figure, over the last 40 years, there are net outflows of New Zealand citizens almost every year. However, these departing New Zealand citizens have been replaced by slightly larger inflows of citizens of other countries. Therefore, to date New Zealand has experienced a replacement migration or exchange, rather than a 'brain drain'.

On a per capita basis, contemporary outflows (and inflows) of New Zealanders are high by comparison with countries of similar size (for example, Ireland, Singapore and Norway) - there is more 'turnover' in the New Zealand population than in these three countries. For example, over the period 1996-1998, in the case of Ireland, gross migration inflows were approximately 1.1 per cent of the total population, and gross outflows about 0.7 per cent of the population, giving a net migration rate of 0.4 per cent. In the case of Norway, the gross inflows and outflows rates over the same period were 0.8 per cent and 0.55 per cent respectively, resulting in a net migration rate of 0.25 per cent (see OECD, 2000). The corresponding figures for New Zealand are 2.0 per cent, 1.5 per cent and 0.5 per cent respectively. One can argue that the high levels of immigration under the points system in New Zealand (high on a per capita basis, again by comparison with Australia, and the US, and similar to Canada) coupled with the significant PLT outflows of New Zealanders, and the persistent return flow of around 20,000 to 22,000 per year, is a clear indication of an exchange rather than either a drain or a gain.

As discussed in more detail in Glass and Choy (2001), there is only relatively unreliable information on the skills of migrants. This is based on the question on the departure and arrival cards that asks for travellers' occupations. In over half 
the cases, there are no data on the occupations of the migrants (there is no requirement to fill in the card completely), and consistent data are available only since 1992. In addition, occupational data are available only for those who identify themselves as PLT migrants. One should bear these limitations in mind when making inferences using such data.

This analysis places occupations into one of three skills levels — high-skilled (New Zealand Standard Classification of Occupations (NZSCO) codes 1 to 3), semi-skilled (NZSCO codes 4 and 5) and low-skilled (NZSCO codes 6 to 9) (see Shevland, 1999). High-skilled includes professionals, associate professionals, technicians, and managers. The semi-skilled group includes clerks, service and sales workers, and the low-skilled category includes people involved with routine production work, and manual labour. The meaning of these terms is not exact, and the terms are used for simplicity, rather than for precision. Some relatively skilled tradespeople (NZSCO code 7) are included in the low-skilled grouping (Humphris, 2001).

Figure 2 compares the three-year average percentages of PLT departures and arrivals in each skill category at the beginning and end of the 1992-2001 period. It is noted that these are percentages of all those who specify an occupation that could be coded.

Figure 2: Skill Distribution of PLT Migration Flows 1992-2001

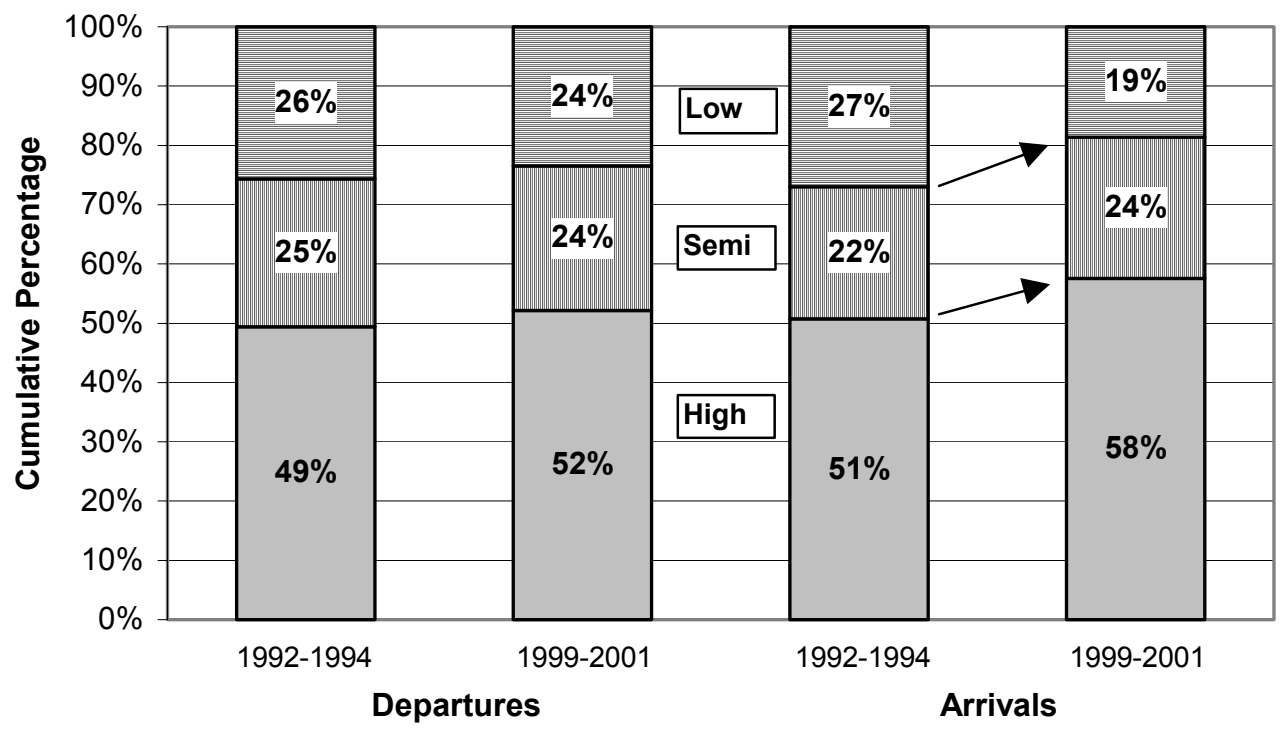

(3-year averages at start and end of the 1992-2001 period) 
Figure 3 below shows how the skills of people migrating to the rest of the world compare with those of the remaining New Zealand population for the 19971999 period.

The data available on occupation seem to suggest that the skill pattern of departures to the rest of the world has not changed much over the last decade, whereas arrivals are getting more skilled, at least in recent years (see Figure 2). Departures to the rest of the world appear to be more skilled than the remaining population (see Figure 3). However, these skill-biased departures to the rest of the world have to be considered alongside the high proportion of high-skilled people immigrating to New Zealand. In fact, there is some evidence that recent arrivals have contained a greater proportion of people in the 'high-skill' category than have departures. In short, there seems to be a brain exchange, rather than a brain drain.

\section{Figure 3: New Zealand's Skill Distribution 1997-1999}

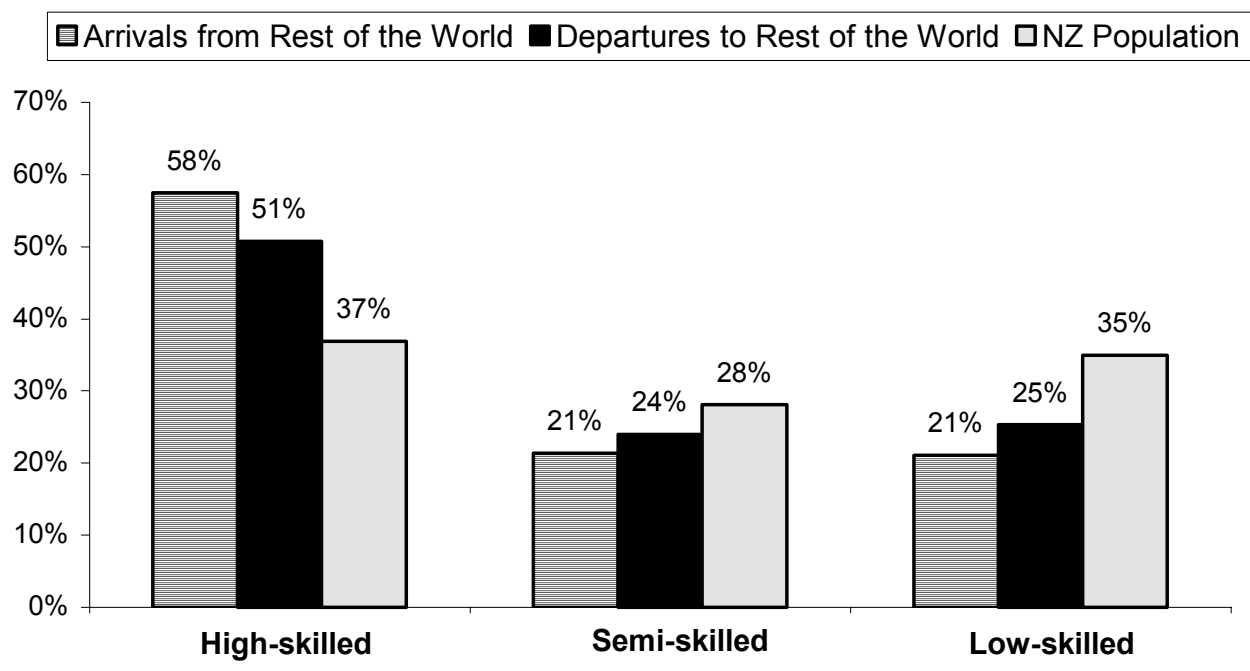

In addition, there is a substantial level of return migration, which could reduce concerns about a brain drain. Since the early 1980s, more than 20,000 New Zealand citizens have been coming back to the country each year (see Lidgard, 1993, 1994 and 2001).

Data on age of PLT migrants seem to suggest that the age of both those departing and arriving have increased. More disaggregated data reveal a drain of younger New Zealanders and a gain of adult non-New Zealand citizens, hence the label 'exchange young people for adults'. Controlling for changes in the age distribution of the remaining population, age-specific emigration rates further support the point that departing New Zealanders have grown older. In particular, the likelihood of emigrating for 15-19 year olds has dropped, while the chances of leaving for 20-29 year olds have increased. 
Trans-Tasman flows are different from those to the rest of the world. A large number of people (predominantly New Zealand citizens) are going westward, and these net outflows are volatile (see Figure 4).

Figure 4: PLT Migration Flows to and from Australia 1947-2001

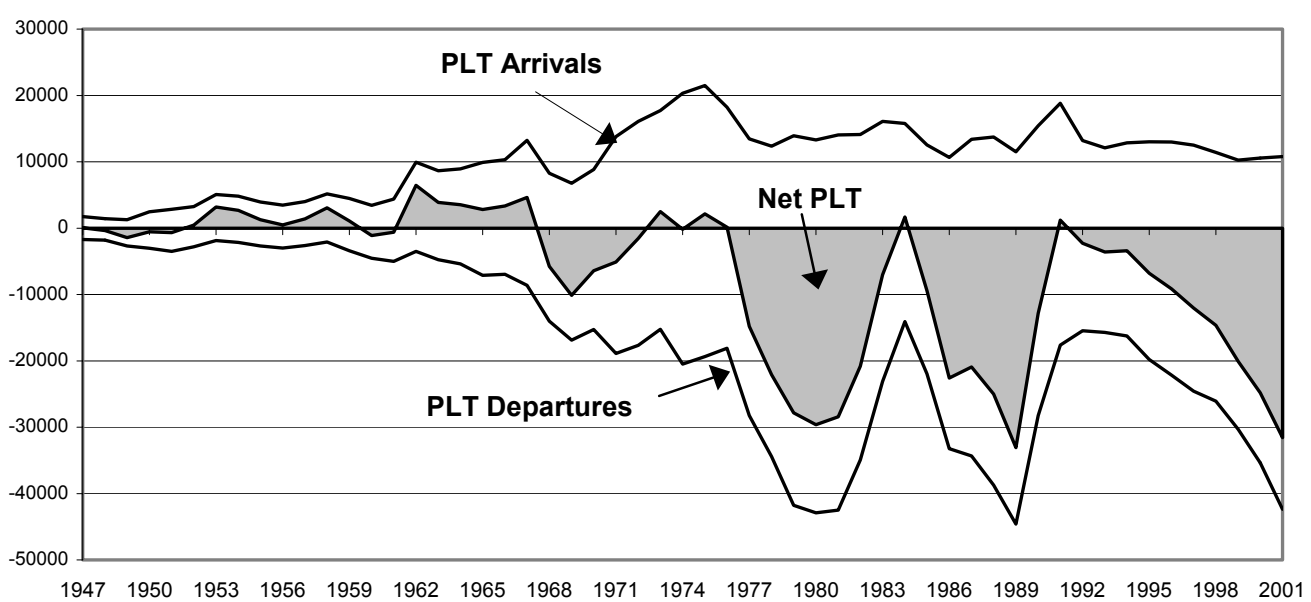

The flow of New Zealand citizens to Australia is not biased toward the highskilled. Instead, it is fairly representative of the remaining population in New Zealand (see Figure 5), hence the label same drain, rather than a brain drain. This evidence is consistent with the existence of a common labour market between the two countries. The main effect of the common labour market has been quite different to a brain drain. Rather than draining only the high-skilled, it has allowed the migration of a broad mix of people, including low-skilled and semiskilled New Zealanders.

\section{Figure 5: Skill Distribution of New Zealand Citizens 1997-1999}

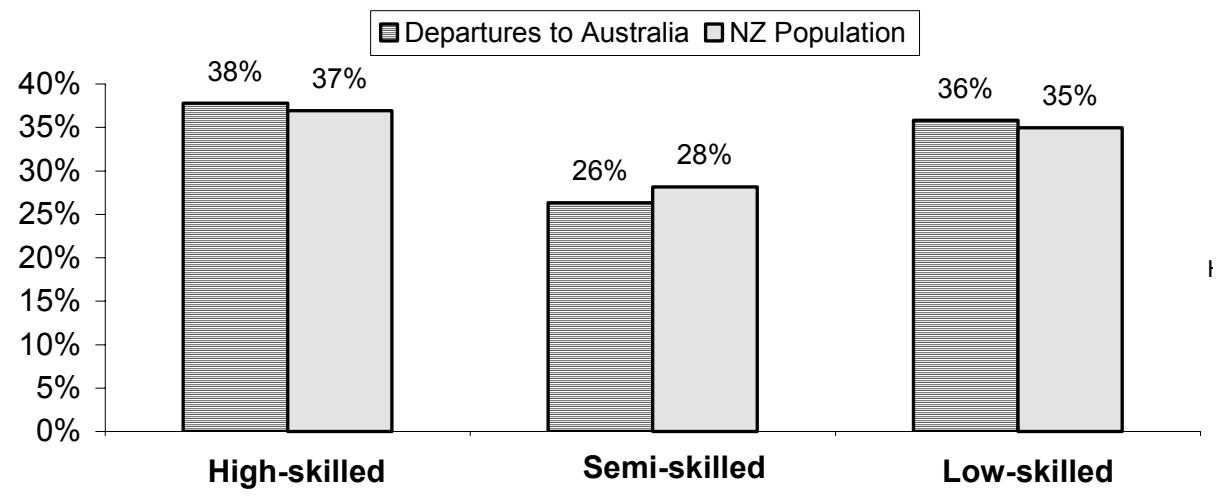


Figures 3 (NZ-Rest of the world) and 5 (NZ-Australia) are not directly comparable because Figure 5 focuses specifically on New Zealand citizens, while Figure 3 looks at all departures, regardless of citizenship. However, our conclusion that departures to the rest of the world are skill-biased but those going to Australia are representative of the remaining population is not affected (see Glass and Choy, 2001).

Birrell et al. (2001) present a different assessment of the evidence in relation to the skill composition of trans-Tasman flows, noting that New Zealand is the largest source country of gain in professionals to Australia. This paper makes somewhat different points from Birrell et al. It looks at the skill mix of the entire flow, while Birrell et al. look at the (large) number of professionals in the flow from New Zealand to Australia (not the share of the flow that are professionals). In addition, the way our data set has been put together differs from that of Birrell et al. This paper focuses on New Zealand citizens, whereas Birrell et al. use New Zealand as a country of last or next permanent residence, and hence they include, for example, Australian citizens and third country citizens who have resided, or are intending to reside, in New Zealand. Another difference is that this paper focuses on PLT movements only, but Birrell et al. analyse total movements (that is, including short-term flows).

\section{Policy Implications}

Table 1 summarises the key pieces of evidence about the numbers, skill and age compositions of migration flows.

Table 1: Summary of Conclusions on a New Zealand Brain Drain

\begin{tabular}{|l|c|c|}
\hline Dimension & NZ-Rest of the World* & NZ-Australia \\
\hline Net Numbers & Inflow & Outflow \\
\hline Skill & Brain exchange & Same drain \\
\hline Age & \multicolumn{2}{|c|}{ Exchange young people for adults } \\
\hline
\end{tabular}

*Rest of the world means all countries, including Australia.

A key issue is not whether migrants are more highly skilled, but whether they integrate well enough into the labour market to be able to make use of those skills.

The unemployment rates of recent migrants are typically high. Winklemann (2000) gives an overall rate of $35 \%$ for migrants in the first year of residence in New Zealand based on 1996 Census data. Rates were substantially lower for younger age groups, and those from English speaking countries, and up to 59\% for 
migrants from South Asia. Similar results are cited in Bedford, Ho and Lidgard (2000) in relation to specific ethnic groups.

Unemployment rates for new labour market entrants are frequently very high. The key question is what happens over time. Poot, Nana and Philpott (1988) present evidence that the likelihood of immigrants being unemployed decreases as time in New Zealand increases. The income of the overseas born who had been in New Zealand 10-14 years in 1981 could be 'favourably compared' with the income of the New Zealand born. Pacific Islanders were particularly disadvantaged on arrival, but tentative evidence suggested that they experienced rapid declines in unemployment and increases in income over time. The explanation for the differences between overseas and New Zealand born focused on skills, and particularly on English language ability.

Results from Winkelmann and Winkelmann (1998) take this point significantly further. Their findings indicate that some immigrants have difficulty integrating into the labour market over time - particularly those from Asia or the Pacific who do not speak English. A typical immigrant, despite being relatively highly educated, was likely to have a lower income and lower probability of participation and employment than a New Zealand-born person of the same age and education level in the first few years after arrival. This entry disadvantage diminished with years of residence in New Zealand. However, there was substantial diversity in relative labour market outcomes. While immigrants from English speaking countries had relatively small initial differentials that tended to disappear within 10 to 20 years of residence, Asian and Pacific Island immigrants had larger initial differentials that were increasing over the study period, and, in some cases, these immigrants were predicted not to reach parity with natives over their working career.

These results suggest that while net migration has added numbers to the New Zealand population over the longer term, the incoming migrants may, in fact, not be a complete replacement for citizens who departed (at least in the short run), despite being apparently higher skilled on average.

Policy changes to respond to these results could target inflows, outflows or both. Selection and settlement policies focus on finding the immigrants most likely to settle well, and helping them to integrate quickly into New Zealand. Finding ways to tap the New Zealand diaspora is one way to cope with outflows. Policy questions relevant for both inflows and outflows include trans-Tasman issues and the ultimate objective of increasing the relative attractiveness of New Zealand. Each of these is discussed in turn. What is obvious from the start is that no one policy setting can affect all aspects of the brain drain issue.

Evidence points to a brain exchange (or a replacement migration), rather than a brain drain. In addition, evidence on the labour market outcomes of immigrants indicates that the degree of substitutability of immigrants for people departing from New Zealand is questionable. These points suggest that New Zealand could gain by focusing on settlement issues and on better helping immigrants integrate into the labour market. 
Settlement policy is part of a broader immigration policy framework. But immigration policy directly affects only the arrivals of those who are not New Zealanders, Australians or from the few Pacific Islands with which New Zealand has special arrangements. If it were considered that outward flows of people are a problem in and of themselves, then an increase in the inward migration target could be one solution. However, it is unclear whether it is sustainable to increase the level of inward migration much further, given that it is already running at about one per cent of total population.

It is also worth noting that patterns of movement are changing and this can influence how immigration and settlement policies should be designed. It is often assumed that international migration is all about people intending to settle permanently in a country, or at least intending to stay for a very long time. The terms 'permanent and long-term migrants' and 'settlers' are thus commonly used.

However, as globalisation trends continue, evidence suggests that migration is less likely to be permanent and long term (Bedford, 2001). People come and go, and travel more frequently than they used to. While the two terms above may have been suitable earlier in the 20th century, reality has changed at least in the last 2 or 3 decades. In fact, only a small part of the total movement of people in and out of New Zealand is this classical 'settlers' migration (Bedford, 2001). Therefore, there is an increasing need to give greater attention to the so-called 'short-term' flows in public and policy debates. For example, work permit policy may need to continue to develop a role as important as residence policy in the immigration framework. Permanent and long-term migration statistics will be less and less useful, while data on temporary movements will become more and more important.

Policy makers might well be concerned if there were significant, ongoing net outflows of the high-skilled. But even in this case, immigration and settlement policies could only help marginally, as much of the inflow, and all of the outflows, are not directly influenced by government policy.

Some have argued that rather than focussing solely on the apparent brain drain, New Zealand should endeavour to attract expatriates (see for example, Bedford, 2001). The means to implement this strategy are unclear. Meyer and Brown (1999) identified 41 expatriate knowledge networks that have been identified around the world. Their list only includes networks that have an explicit purpose of connecting the expatriates among themselves and with the country of origin and of promoting the exchange of skills and knowledge. These networks differ in size, scope, objectives, activities and structure, and are tied to 30 different countries, such as Ireland, France, Korea, Taiwan, and Norway. New Zealand did not have an explicit network identified by the authors.

As pointed out by Meyer and Brown (1999), it is often difficult to assess the success of these networks in terms of their contribution to the development of the source country. The types of exchanges that take place between network members and the national community - for instance, email and data exchanges, virtual chat rooms, informal advisory opinions etc. - do not always bring tangible, visible or immediate results and may not allow for a statistical assessment. However, it does 
not mean that these exchanges are not important (see Spoonley, Bedford and Macpherson, 2000).

It may be that some way of harnessing the potential of New Zealanders overseas can be found. While the possibility is favoured by some commentators (Bedford, Ho and Lidgard, 2000; ITAG, 1999), there have been few concrete suggestions for what might be done. The experience of countries such as Ireland and India that already have implemented these kinds of policies, may provide some useful lessons (see Meyer and Brown, 1999). This strategy is increasingly becoming part of the public and academic debate, as can be seen from the recent Catching the Knowledge Wave conference in Auckland, August 2001 (see http://www.knowledgewave.org.nz/index_home.cfm).

Over the past 30 years, the net trans-Tasman flow has been almost always toward Australia from New Zealand. The large continuing imbalance has led to concerns about two particular areas, viz: the different criteria for third country migrants, and the fiscal costs of social security payments (see Bushnell and Choy, 2001). They have been resolved in the case of welfare payments by redesigning the underlying policies. In the case of migration from third countries small differences in criteria have been tolerated so far.

The new Australia-New Zealand Social Security Agreement could well have some implications on the brain drain debate (see http://www.nz-oz.gov.au/; Birrell and Rapson, 2001). For those who would not qualify under Australian immigration criteria, the new agreement would have an impact on their decision to migrate to Australia and/or the length of stay once in Australia. Therefore, it may affect the composition of workforce going over to Australia, as well as those returning to New Zealand.

There may be a small impact on the ex ante brain gain effect through migrants that seek to improve their career prospects but are starting from a lowbase in terms of human capital (that is, those who tend to be classified as lowskilled). However, the impact is likely to be relatively minor because the ex ante brain gain effect applies particularly to those seeking higher education.

Even without convincing evidence of a brain drain, New Zealand faces a challenge. There is, and will continue to be, increasing competition in the international labour market for high-skilled people, as a result of shortages of labour in particular occupations, and the ageing of population globally.

In terms of retaining people within New Zealand, there are very few possible controls on departures of any group. The immigration rules of other countries determine their emigration options. To the extent that departures are caused by push factors (for example, there is wide speculation that the student loan rules are a driver), evening out enforcement across countries (tax agreements with Australia and the United Kingdom may be of value) will help reduce any distortions on departures (For more information on the student loan scheme in New Zealand, see the annual report to June 2001 prepared by the Ministry of Education, Inland Revenue and Work and Income New Zealand). In terms of attracting high-skilled workers, there may be scope for improving settlement and selection policies as mentioned earlier. 
Ultimately, New Zealand should focus on increasing its attractiveness (for attracting highly-skilled immigrants and return migrants, and retaining existing residents) by improving the economic position of New Zealand relative to competitor countries. One way is to raise productivity more generally, leading to higher wages to attract the high-skilled. Another way is to encourage the use of more high-skill technologies, so that the high-skilled have opportunities here. However, these two strategies are endogenous with attracting and retaining highskilled people. Therefore, both need to be part of a longer term strategy; there is no quick short-term solution.

\section{Summary and Concluding Remarks}

From an economic perspective focused on well-being, there could be a cause for public policy concern if any of the following held in the medium to long term:

- There were net outflows of the high-skilled, and no rationing of entry to the destination country. Without rationing, there is no ex ante brain gain effect (where people are generally encouraged to upskill by the prospect of high returns from emigrating), and only a negative effect on the human capital of the source country from emigration.

- There were net outflows of the highly-experienced. Age is an indicator of the depth and breadth of work experience. Thus if New Zealand were losing those in the middle labour force age groups, this could be cause for concern.

- There were net outflows of the high-skilled and limited return migration. Net outflows of the high-skilled can be useful if these people come home still higher-skilled at some point in the future. If they do not, then this may be a problem.

- There were other significant negative social, fiscal or economic impacts from net outflows of the high-skilled.

The key findings from the data are:

- $\quad$ There are no net outflows in the medium to long-term - We conclude that New Zealand is experiencing a brain exchange with the world (with more people coming in than going out, and those coming in more skilled than those leaving), and a same drain with Australia (where there are more leaving than coming, but the departures are not biased towards the high-skilled).

- We switch young adults for slightly older adults - On age profile, we are likely to be importing migrants who are more experienced in the labour market than the emigrants we are losing.

- $\quad$ There is substantial return migration - Since the early 1980s, more than 20,000 New Zealand citizens have been coming back to the country each year. 
In addition there is some evidence that immigrants often have a hard time finding jobs to make use of their high skills. If immigrants are not good replacements for those leaving New Zealand, then this could lead to loss of human capital. Enhancements to immigration selection policies (to identify those likely to settle best) and to settlement policy (to the extent that assistance to immigrants after they arrive can help) may reduce concerns on this point.

There is a large population of overseas-resident New Zealanders. While many people consider that some kind of 'remote mobilisation' of these people is a good idea, there are but few concrete suggestions for how to go about it.

Policy makers should monitor the skill distribution of immigrants and emigrants. Changes to improve the quality of the data available from arrival and departure cards might pay dividends in the longer term.

Even without compelling evidence of a brain drain, it is sobering that so many New Zealanders continue to choose to leave New Zealand over the long term. There is, and will continue to be, increasing competition in the international labour market for high-skilled people, as a result of shortages of labour in particular occupations, and the ageing of population globally. Ultimately, New Zealand should focus on increasing its attractiveness (for attracting highly-skilled immigrants and return migrants, and retaining existing residents) by improving its economic position relative to competitor countries. This is something that cannot be done overnight.

To conclude, there is a need to move the public debate on immigration and emigration away from reactions to short-term and volatile numbers, to a longerterm perspective, and towards a more sophisticated conception of what will be an ongoing trend - that is, the increasingly free flow of people, including New Zealanders, around the globe.

\section{References}

Bedford, R. (2001), 'Reflections on the Spatial Odysseys of New Zealanders', New Zealand Geographer 57(1):37-42.

Bedford, R. and C. Bedford (2001), 'International Migration Up-Date: Processes and Policies, September 2001', New Zealand Journal of Geography 112:23-30.

Bedford, R., E. Ho, and J. Lidgard (2000), 'Immigration Policy and New Zealand's Development into the $21^{\text {st }}$ Century: Review and Speculation', Paper presented to APECHRD-LSP Ninth International Workshop on 'International Migration and Structural Change in APEC Member Economies'.

Beine, M., D. Docquier and H. Rapoport (2001), 'Brain Drain and Economic Growth: Theory and Evidence', Journal of Development Economics 64:275-289.

Bhagwati, J. and K. Hamada (1974), 'The Brain Drain, International Integration of Markets for Professionals and Unemployment: A Theoretical Analysis', Journal of Development Economics 1(1):19-24. 
Birrell, B., I. Dobson, V. Rapson and F. Smith (2001), 'Skilled Labour: Gains and Losses', DIMA Report, Department of Immigration and Multicultural Affairs, Canberra, July, (http://www.dima.gov.au/research/publications/skilledlab/index.htm).

Birrell, B. and V. Rapson (2001), 'New Zealanders in Australia: The End of An Era', People and Place 9(1):61-74.

Bushnell, P. and W. Choy, (2001), 'Go West, Young Man, Go West!', People and Place 9(3):66-83.

Carmichael, G. (ed.) (1993a), Trans-Tasman Migration: Trends, Causes and Consequences, Australian Government Publishing Service, Canberra.

Carmichael, G. (1993b), 'Beware the Passenger Card! Australian and New Zealand Data on Population Movement Between the Two Countries', International Migration Review 27(1):819-849.

Carrington, W. and E. Detragiache (1998), 'How Big is the Brain Drain?', IMF Working Paper WP/98/102, July, (see http://www.imf.org/).

Claridge, M. and S. Box (2000), 'Economic Integration, Sovereignty and Identity: New Zealand in the Global Economy', Treasury Working Paper 00/22, New Zealand Treasury, (see http://www.treasury.govt.nz/workingpapers/).

Glass, H. and W. Choy (2001), 'Brain Drain or Brain Exchange?', Treasury Working Paper 01/22, New Zealand Treasury, (see http://www.treasury.govt.nz/workingpapers/).

Golden, C. and L. Katz (1998), 'The Origins of Technology-Skill Complementarity', Quarterly Journal of Economics 108:693-732.

Hague, N. and S. Kim (1995), 'Human Capital Flight': Impact of Migration on Income and Growth, IMF Staff Papers 42(3):577-607.

Hamermesh, D. (1993), Labor Demand, Princeton University Press, Princeton NJ.

Humphris, J. (2001), 'Descriptive Analysis of Emigration Patterns of New Zealand Citizens, Using Data from New Zealand Arrival and Departure Cards', Labour Market Policy Group, New Zealand Department of Labour, Unpublished Paper, March.

ITAG (Information Technology Advisory Group to the Minister of Information Technology) (1999), 'The Knowledge Economy', Submission to the New Zealand Government.

Johnson, J. and M. Regets (1998), 'International Mobility of Scientists and Engineers to the United States - Brain Drain or Brain Circulation?', National Science Foundation, Directorate for Social, Behavioral and Economic Sciences, NSF 98-316, November 10. (www.nsf.gov/sbe/srs/issuebrf/sib98316.htm). 
Krusell, P., L. Ohanian, J. Ríos-Rull and G. Violante (1997), 'Capital-Skill Complementarity and Inequality: A Macroeconomic Analysis', Research Department Staff Report 239, Federal Reserve Bank of Minneapolis.

Lidgard, J. (1993), 'Neglected International Migrants: A Study of Returning New Zealanders', New Zealand Population Review 19:94-124.

Lidgard, J. (1994), 'Return Migration of New Zealanders: A Profile of 1990 Returnees', New Zealand Journal of Geography 97(1):3-13.

Lidgard, J. (2001), 'Return Migration of New Zealanders: A Profile of Returnees in 2000', New Zealand Journal of Geography 112:10-17.

Meyer, J. and M. Brown (1999), 'Scientific Diasporas: A New Approach to the Brain Drain', Paper prepared for the 'World Conference on Science', UNESCO-ICSU, Budapest, Hungary, 26 June 1999, (http://www.unesco.org/most/meyer.htm).

Ministry of Education, Inland Revenue and Work and Income New Zealand (2001), 'Student Loan Scheme Annual Report to 30 June 2001', Wellington, (http://www.minedu.govt.nz/web/downloadable/d16571_v1/01\%2D12\%20Dec\%20m\%2E o\%2Ee\%20SLS\%20report.pdf).

Mountford, A. (1997), 'Can a Brain Drain Be Good for Growth in the Source Economy?', Journal of Development Economics 53:287-303.

New Zealand Institute of Economic Research (1994), 'Literature Review on the Economic Impact of Immigration', Report to New Zealand Department of Labour, Working Paper $95 / 5$.

New Zealand Institute of Economic Research (1996), 'A Framework for the Assessment of the Economic and Social Effects of Immigration', Report to the New Zealand Department of Labour.

OECD (2000), Trends in International Migration: Continuous Reporting System on Migration - Annual Report, Organisation for Economic Co-operation and Development, Paris.

Poot, J., G. Nana and B. Philpott (1988), International Migration and the New Zealand Economy: A Long-run Perspective, Institute of Policy Studies, Victoria University of Wellington.

Shevland, M. (1999), 'Recent External Migration Flows of Skilled New Zealand Workers', Unpublished Report, Ministry of Education.

Spoonley, P., R. Bedford and C. Macpherson (2000), 'Divided Loyalties and Fractured Sovereignty: Transnationalism and the State in Aotearoa/New Zealand', Paper presented at the workshop 'The Role of the State in the Transnational Moment', Fifth International Metropolis Conference, Vancouver, 13-17 November 2000. 
Stark, O., C. Helmenstein and A. Prskawetz, (1997), 'A Brain Gain with a Brain Drain', Economics Letters 55:227-234.

Winkelmann, L. and R. Winkelmann (1998), 'Immigrants in New Zealand: A Study of their Labour Market Outcomes', Occasional Paper 1998/1 for the Labour Market Policy Group, Department of Labour, Wellington.

The authors would like to thank particularly Richard Bedford, David Maré, and Grant Scobie for valuable input and comments on numerous previous drafts and antecedent papers. Helpful comments were received from two anonymous referees. All errors, omissions and views in this paper are those of the authors. 